\title{
BMJ Open A systematic review of eculizumab for atypical haemolytic uraemic syndrome (aHUS)
}

\author{
John Rathbone, ${ }^{1}$ Eva Kaltenthaler, ${ }^{1}$ Anna Richards, ${ }^{2}$ Paul Tappenden, ${ }^{1}$ \\ Alice Bessey, ${ }^{1}$ Anna Cantrell ${ }^{1}$
}

To cite: Rathbone J, Kaltenthaler $\mathrm{E}$, Richards $\mathrm{A}$, et al. A systematic review of eculizumab for atypical haemolytic uraemic syndrome (aHUS). BMJ Open 2013;3:e003573.

doi:10.1136/bmjopen-2013003573

- Prepublication history for this paper is available online. To view these files please visit the journal online (http://dx.doi.org/10.1136/ bmjopen-2013-003573).

Received 10 July 2013 Revised 5 September 2013 Accepted 4 October 2013

CrossMark

\author{
${ }^{1}$ School of Health and \\ Related Research, University \\ of Sheffield, Sheffield, UK \\ ${ }^{2}$ Centre for Complement \& \\ Inflammation Research, \\ Imperial College, London, UK
}

Correspondence to Dr Eva Kaltenthaler; e.kaltenthaler@sheffield.ac.uk

\section{ABSTRACT}

Objective: To determine the efficacy and safety of eculizumab for patients with atypical haemolytic uraemic syndrome (aHUS), compared with current treatment options.

Design: A systematic review was performed according to the general principles of the Preferred Reporting Items for Systematic Reviews and Meta-Analyses (PRISMA) statement. All study designs were included, except case histories.

Participants: All patients diagnosed with aHUS were included; no age restrictions were used.

Interventions: Eculizumab compared with current treatment options.

Identification of studies: 12 databases were searched. Additional searches were performed through the Food and Drug Administration (FDA) and the Electronic Medicines Compendium websites, Google internet searches and contacting clinical experts. Reference lists of relevant articles were checked for additional studies.

Results: 2 small, uncontrolled prospective multinational, multicentre studies and one small uncontrolled multinational, multicentre retrospective study were included. No meta-analyses were performed. Compared with baseline measures, thrombotic microangiopathy event-free status was achieved in $84 \%$ of patients in the prospective studies. Adverse events, as documented by enrolling investigators were frequent, with upperrespiratory tract infection affecting a third of patients. No deaths or episodes of meningitis or meningococcal septicaemia occurred in the prospective studies. Results of the study extension phases up to 114 weeks indicate that the benefits of the treatment are sustained.

Conclusions: Eculizumab is clinically effective for the treatment of aHUS. Further research is needed to evaluate eculizumab, ideally using patient-related clinical outcomes. If randomised studies are not feasible, study investigators should ensure that the threat of bias is minimised in future studies of eculizumab with respect to the reporting of patient recruitment and selection.

\section{INTRODUCTION}

Haemolytic uraemic syndrome (HUS) is defined as an acute onset of renal impairment with increased serum urea and

\section{Strengths and limitations of this study}

- Follow-up data at 2 years indicate that benefits of treatment are sustained.

- Adverse events were frequent, although no severe life-threatening adverse events were associated with treatment.

- The small number of patients included in these uncontrolled studies and the use of surrogate markers is a limiting factor and the inference of treatment effects may be confounded.

creatinine levels, thrombocytopenia (platelet count $<150 \times 10^{9} / \mathrm{L}$ ) and microangiopathic haemolytic anaemia (haemoglobin $<10 \mathrm{~g}$ / dL). ${ }^{1}{ }^{2}$ It is most usefully classified according to the underlying aetiology. ${ }^{3}$ The commonest cause of HUS (90\%) is Shiga toxin-mediated HUS (Stx-HUS), historically defined as 'typical HUS'. A second type of HUS, known as atypical HUS (aHUS) is aetiologically distinct and may be familial $(20 \%)$ or sporadic $(80 \%) .{ }^{4}$ aHUS is classed as a rare or ultraorphan disease, which in the UK describes conditions with a prevalence of $<1$ case/ 50000 population. ${ }^{5}$ There are approximately 170 people with aHUS in the UK. The European community data estimate the incidence of aHUS to be 2 per million population and prevalence as 7 cases per million in children. ${ }^{6}$ Recent data have shown that the onset of aHUS is as frequent in adulthood $(58.4 \%)$ as in childhood $(41.6 \%)$. Seventy per cent of all cases studied $(n=214)$ had presented by 40 years of age. ${ }^{7}$

aHUS commonly develops due to dysregulation of the alternative pathway of complement. To date, mutations in the complement regulatory genes factor $H(C F H, 20-30 \%)$, membrane cofactor protein $(C D 46,10$ $15 \%)$, factor $I \quad(C F I, \quad 5-10 \%)$ and Thrombomodulin (THBD, 3-5\%); the activatory genes factor $B(C F B, 1-4 \%)$ and $C 3$ (2$10 \%)$ and autoantibodies to $\mathrm{CFH}(6-10 \%)$ 
have been described and account for $50-60 \%$ of aetiologically defined aHUS. ${ }^{4} 8$ Mutations causing an aHUS-like phenotype are also reported in noncomplement pathway genes, for example, in $M M A C H C^{9}$ and $M T R R^{10}$ genes of the cobalamin pathway and the lipid kinase diacylglycerol kinase epsilon (DGKE) gene. ${ }^{11}$

The natural history of aHUS relates to the underlying genetic mutation, and historically it has been a condition with a poor prognosis. More than $60 \%$ of patients with mutations in $C F H, C F I, C 3, F B$ or $T H B D$ die or develop end-stage renal disease (ESRD) or death despite active treatment within 1 year of presentation. ${ }^{12}$ Patients with CD46 mutations have a better long-term outcome, with $30 \%$ progressing to ESRD, despite a frequently relapsing course. ${ }^{13}$ The mortality rate is higher in children than in adults $(6.7 \%$ vs $0.8 \%$ at 1 year, $\mathrm{p}=0.02)$, but progression to ESRD was more frequent in adults $(46 \%$ vs $16 \%, \mathrm{p}<0.001){ }^{7}$

Evaluating a role for eculizumab in the management of aHUS requires an assessment of previous best practice. In addition to supportive care and dialysis, the mainstay of treatment for acute or relapsing episodes of aHUS was plasma infusion (PI) or plasma exchange (PE) therapy. Outcomes of plasmapheresis for aHUS have recently been reviewed ${ }^{4}{ }^{14}$; although around $60 \%$ of patients with aHUS respond initially, ${ }^{15}$ historical reports suggest that $50 \%$ are left with chronic kidney injury. ${ }^{16}$ In those with factor $\mathrm{H}$ autoantibody aHUS, the antibody titre often rises after plasmapheresis is discontinued and aHUS recurs. The chance of relapses may be significantly reduced by the addition of an immunosuppressive therapy. The choice of agent is not currently standardised but has included steroids, mycophenolate mofetil, cyclophosphamide and rituximab. ${ }^{4}$

Overall, plasmapheresis is a safe procedure with a mortality rate of less than 1 in $10000 \mathrm{PE}$ procedures. ${ }^{14} 17$ Potential complications include risks associated with vascular access insertion, infection; fluid balance changes during the procedure; hypersensitivity reactions; a small risk of viral transmission from plasma; and reduced patient tolerance over the longer term leading to treatment withdrawal. ${ }^{14} 18$ Plasmapheresis in children has recently been reviewed. It can be performed safely but has additional technical challenges. There are high rates of catheter-related thrombosis and infection and a need to modify treatments to avoid complications from the relatively large extracorporeal blood volumes needed to use the automated apheresis equipment. ${ }^{19}$

For those with end-stage kidney disease on long-term dialysis, options have been very restrictive. This is because isolated renal transplantation in those with soluble protein mutations in, for example, factor $\mathrm{H}$ or factor I, is associated with extremely high rates of graft loss due to the recurrence of aHUS. As such, isolated renal transplantation cannot normally be recommended. ${ }^{20}$ Attempts to overcome this issue included a small number of reports of renal transplantation with the addition of long-term $\mathrm{PE}^{15}$ or use of combined liver-kidney transplantation. ${ }^{21}$ Liver-kidney transplantation has been successful, but has a significant procedural morbidity rate and risk of death. There is a clear need for the development of alternative therapeutic strategies in aHUS for primary treatment and to facilitate renal transplantation.

A previous systematic review of HUS interventions (literature included up to June 2006), was published in 2009. Seven randomised controlled trials (RCTs) in 476 young children, who predominantly had Stx-HUS were included. There were many limitations, of which the small number of participants with aHUS and the failure of five of the seven trials to recruit and to report results for atypical and typical HUS separately are of particular relevance to this work. None of the interventions studied were superior to supportive therapy in patients with Stx-HUS. ${ }^{2}$ No RCTs specifically evaluating the effectiveness of any intervention including PE or PI were found for patients with aHUS. ${ }^{2}$

Eculizumab is a new therapy being tested in patients with aHUS. Eculizumab (Soliris) is a humanised monoclonal IgG2 $/ 4 \kappa$ antibody produced from murine myeloma cells by recombinant DNA technology. It acts as a complement inhibitor, binding specifically to complement protein C5 with high affinity, thereby inhibiting cleavage to $\mathrm{C} 5 \mathrm{a}$, a prothrombotic and proinflammatory molecule and C5b, preventing the generation of the terminal complement complex C5b-9. ${ }^{22}$ It was originally tested for rheumatoid arthritis without success, but is now used routinely for paroxysmal nocturnal haemoglobinuria $(\mathrm{PNH}){ }^{23}$ It is licensed by the European Medicines Agency (EMA), and the US Food and Drug Administration (FDA) for treatment of aHUS. ${ }^{24}$ The drug is not yet widely available in the UK.

\section{METHODS}

We undertook a systematic review with the aim of assessing the evidence for the efficacy and safety of eculizumab for patients with aHUS, compared against current treatment options. A protocol was developed and a systematic review performed according to the general principles recommended in the Preferred Reporting Items for Systematic Reviews and Meta-Analyses (PRISMA) statement. $^{25}$

\section{Inclusion criteria}

Studies were included if patients had a diagnosis of aHUS (no age restrictions were used) and received eculizumab. Relevant comparators were PI, PE, dialysis and renal transplantation. All study designs were included, except case histories.

\section{Identification of studies}

We sought relevant studies by searching the following databases: MEDLINE (1966 to January 2012), EMBASE (1980 to January 2012), MEDLINE In-Process (January 2012), Biological Abstracts (1985 to January 2012), NHS 
EED (January 2012), NHS HTA (January 2012), Web of Science (1899 to December 2010), CENTRAL/CCTR (January 2012), CDSR (January 2012), CINAHL (1982 to January 2012), Citation Indexes (Science and Social Sciences; January 2012), DARE (January 2012). Ongoing trials were sought using ClinicalTrials.gov, Current Controlled Trials and UKCRN Portfolio database. For grey literature, OpenGrey database was searched. Authors were contacted for additional data and searches of the US FDA and Electronic Medicines Compendium websites were also undertaken to obtain further data. An update search was undertaken in June 2013. The search strategy was designed to identify all studies with no language restriction (see online supplement 1).

\section{Study selection and data extraction}

Titles and abstracts were independently screened for relevance by two reviewers (JR and EK) and full text reports of potentially relevant studies were inspected for inclusion. Where disagreements occurred, resolution was achieved by discussion and where doubt remained, a third reviewer was consulted. Data were abstracted by two reviewers (JR and EK), quality assessed and crosschecked for accuracy.

\section{Assessment of study quality}

The prospective studies identified by the search were appraised using checklist criteria for non-randomised studies adapted from Chambers. ${ }^{26}$ The quality of the retrospective study was not assessed due to the inherent biases associated with this study design and the lack of a control group.

\section{RESULTS}

\section{Study selection}

The database search identified 1398 citations. Nine further citations were identified from additional searches from other sources. Once duplicates were removed, 1218 citations were excluded at the title/ abstract stage and 189 articles were obtained for examination of the full text. Of these, 176 were excluded because they did not meet the inclusion criteria. In total, three studies were identified from the searches, relating to 13 citations (PRISMA diagram, see online supplement 2).

\section{Study characteristics}

Of the three studies, two were prospective, open-label, single-arm studies $\left(\mathrm{C} 08-002^{27-34}\right.$ and C08-003 $\left.{ }^{33-36}\right)$. Study C08-002 (trial $1^{37}$ ) included patients in the early phase of aHUS who were resistant to plasma therapy, while patients in C08-003 (trial $2^{37}$ ) had longer term aHUS and were receiving maintenance plasma therapy. The third study was a retrospective single arm study $\left(\mathrm{C} 09-001 \mathrm{R}^{38}{ }^{39}\right)$ with 15 paediatric patients. Details of the study characteristics are shown in online supplement 3 .

\section{Risk of bias assessment}

A summary of the risk of bias in studies C08-002 and C08-003 is presented in online supplement 4. Bias was assessed using a modified assessment criteria for case series. ${ }^{26}$ The quality of study C09-001R was not assessed due to the inherent biases associated with retrospective study designs.

Selection criteria were reported in both studies, but patient eligibility was not clearly described. It is unclear how patients were selected or whether all patients identified with aHUS who fitted the inclusion criteria were included in the studies. It is unclear whether study populations derived from multiple multinational specialist centres can be considered representative of patients with aHUS seen in routine clinical practice. Both studies restricted the population to include only patients with age $>12$ years.

Appropriate measures of variability were used in both studies, with CIs reported around the points estimate to indicate variability. Loss to follow-up and reasons for leaving the studies early were reported in both studies, and more than $90 \%$ of those included at baseline were followed up. It is not clear from the study reports whether patients were recruited prospectively. Patients were not recruited consecutively which introduces potential for recruitment bias. Prognostic factors such as complement abnormalities and biochemical tests were reported for both studies.

\section{Results of individual studies}

Table 1 shows the main efficacy results for the two prospective studies. In both prospective studies, change in platelet count from baseline to week 26 was significantly different at the $95 \%$ confidence level. In study C08-002, 14 of 17 patients $(82 \%)$ were reported to have a normal platelet count. In study C08-003, platelet count normalisation occurred in 18 of $20(90 \%)$ patients.

In study C08-002, 15 of 17 patients (88\%) achieved thrombotic microangiopathy (TMA) event-free status, while in study C08-003, $80 \%$ of patients achieved TMA event-free status (defined as $\geq 12$ weeks of stable platelet count, no PE/PI and no new dialysis). In studies C08-002 and C08-003, the daily median TMA intervention rate, defined as the number of PE or PI interventions and number of new dialyses required per patient per day, measured from pre-eculizumab to study endpoint was significantly different $(\mathrm{p}<0.0001)$. Both studies C08-002 and C08-003 reported chronic kidney disease (CKD) improvement by $\geq 1$ stage. In study C08-002, 10 of 17 patients (59\%) showed improvement. In study C08-003, 7 of 20 patients $(35 \%)$ showed improvement in kidney function. The median estimated glomerular filtration rate (eGFR) change at 26 weeks was $20 \mathrm{~mL} / \mathrm{min} / 1.73 \mathrm{~m}^{2}$ (median range -1 to 98 ) in study C08-002. In study C08-003, the median change in eGFR was $5 \mathrm{~mL} / \mathrm{min} / 1.73 \mathrm{~m}^{2}$ (median range -1 to 20 ). Improvement in eGFR of $\geq 15 \mathrm{~mL} / \mathrm{min}$ was observed in 9 of 17 patients (53\%) in study C08-002 and only one patient (5\%) in study C08-003. 
Table 1 Efficacy results of prospective studies C08-002 and C08-003 by week 26

\begin{tabular}{|c|c|c|}
\hline Outcomes & C08-002 (n=17) & C08-003 (n=20) \\
\hline Change in platelet count from baseline through & $73(40$ to 105$)$ & $5(-17.5$ to 28$)$ \\
\hline Week $26\left(\times 10^{9} / \mathrm{L}\right)$, point estimate $(95 \% \mathrm{Cl})$ & $p=0.0001$ & $p=0.64$ \\
\hline \multicolumn{3}{|l|}{ Normalisation of platelet count } \\
\hline All patients, $\mathrm{n}(\%)(95 \% \mathrm{Cl})$ & $14(82)(57$ to 96$)$ & $18(90)(68$ to 99$)$ \\
\hline Patients with abnormal baseline, $\mathrm{n}(\%)$ & $13 / 15(87 \%)$ & $3 / 20(15 \%)$ \\
\hline TMA event-free status ${ }^{*}, \mathrm{n}(\%)(95 \% \mathrm{Cl})$ & $15(88)(64$ to 99$)$ & $16(80)(56$ to 94$)$ \\
\hline \multicolumn{3}{|l|}{ TMA intervention rate $\dagger$} \\
\hline Daily pre-eculizumab rate, median (minimum, maximum) & $0.88(0.04,1.59)$ & $0.23(0.05,1.09)$ \\
\hline Daily posteculizumab rate, median (minimum, maximum) & $0(0,0.31)$ & 0 \\
\hline $\mathrm{p}$ Value & $\mathrm{p}<0.0001$ & $\mathrm{p}<0.0001$ \\
\hline CKD improvement by $\geq 1$ stage, $n(\%)(95 \% \mathrm{Cl})$ & $10(59)(33$ to 82$)$ & $7(35)(15$ to 59$)$ \\
\hline eGFR change $\mathrm{mL} / \mathrm{min} / 1.73 \mathrm{~m}^{2}$, median (range) at 26 weeks & $20(-1$ to 98$)$ & $5(-1$ to 20$)$ \\
\hline eGFR improvement $\geq 15 \mathrm{~mL} / \mathrm{min} / 1.73 \mathrm{~m}^{2}, \mathrm{n}(\%)(95 \% \mathrm{Cl})$ & 9 (53) (28 to 77$)$ & $1(5)(0$ to 25$)$ \\
\hline Change in $\mathrm{Hb}>20 \mathrm{~g} / \mathrm{L}, \mathrm{n}(\%)(95 \% \mathrm{Cl})$ & $11(65)(38$ to 86$)$ & $9(45)(23$ to 68$)$ \\
\hline Haematological normalisation $\ddagger$, $n(\%)(95 \% \mathrm{Cl})$ & $13(76)(50$ to 93$)$ & $18(90)(68$ to 99$)$ \\
\hline Complete TMA response§, $\mathrm{n}(\%)(95 \% \mathrm{Cl})$ & $11(65)(38$ to 86$)$ & $5(25)(9$ to 49$)$ \\
\hline Death & 0 & 0 \\
\hline \multicolumn{3}{|c|}{$\begin{array}{l}\text { *TMA event-free status is } \geq 12 \text { weeks of stable platelet count, no PE/PI and no new dialysis. } \\
\text { †TMA intervention rate is the number of PE or PI interventions and number of new dialyses required per patient per day. } \\
\text { fHaematological normalisation is the normal platelet and lactate dehydrogenase levels, } \geq 2 \text { consecutive measurements and } \geq 4 \text { weeks apart. } \\
\text { §Complete TMA response is haematological normalisation plus at least a } 25 \% \text { reduction in serum creatinine for a minimum of } 4 \text { weeks. } \\
\text { Source: Electronic Medicines Compendium. }{ }^{31} \\
\text { CKD, chronic kidney disease; eGFR, estimated glomerular filtration rate; Hb, haemoglobin; PE, plasma exchange; PI, plasma infusion; TMA, } \\
\text { thrombotic microangiopathy. }\end{array}$} \\
\hline
\end{tabular}

In study C08-002, haemoglobin level improved in 11 of $17(65 \%)$ patients, although three patients did receive erythropoiesis stimulating agent (ESA) prior to receiving eculizumab. In study C08-003, 9 of $20(45 \%)$ patients showed improvement in haemoglobin; however, eight patients received ESA which was discontinued in three patients during eculizumab therapy. In study C08-002, complete TMA response, (defined as haematological normalisation, and $\mathrm{a} \geq 25 \%$ reduction in serum creatinine sustained in $\geq 2$ consecutive measurements for $\geq 4$ weeks) occurred in 11 of 17 patients $(65 \%)$; in C08-003, 25\% (5/20) of patients achieved a complete TMA response. No deaths occurred in the two prospective studies at a median follow-up period of 64 weeks (study C08-002) and 62 weeks (study C08-003).

\section{Follow-up data week 40, and median week 114 (study C08-003)}

Nineteen patients continued into the extension phase and data analysis was reported on 19 patients using an intention-to-treat (ITT) design. ${ }^{40}{ }^{41}$ At week 40, 16 of 20 patients $(80 \%)$ remained TMA event free during eculizumab treatment. By median follow-up at 114 weeks, the 19 patients that continued eculizumab treatment remained TMA event free $(95 \%)$. TMA intervention rate was significantly different $(p<0.001)$ from baseline at week 40. Improvement in CKD stage was maintained in 7 of 19 patients $(35 \%)$ achieving $\geq 1$ CKD stage improvement at week 40 , and this had increased to $60 \%(12 / 19)$ by median 114 weeks. Quality of life (QoL; EuroQoL 5D score) was significantly improved $(\mathrm{p}<0.0001)$ at week 40 with $73 \%$ achieving a minimally important difference in QoL. Further improvements in proteinuria (decrease $\geq 1$ grade) occurred at 114 weeks in $80 \%(12 / 15)$ of patients; serum creatinine decrease $(\geq 25 \%)$ was achieved in $55 \%$ of patients at week 114 . The proportion of patients with improved renal function (eGFR $\geq 15 \mathrm{~mL} / \mathrm{min} / 1.73 \mathrm{~m}^{2}$ ) increased from $5 \%$ (26 weeks) to $40 \%$ (114 weeks). The mean eGFR change of $7.1 \mathrm{~mL} /$ $\min / 1.73 \mathrm{~m}^{2}$ by week 96 was significantly improved $(\mathrm{p}=0.05)$.

\section{Follow-up data at week 100 (study C08-002)}

Thirteen patients entered the extension phase and data analysis was reported on ITT population $(n=17) .{ }^{42}$ Mean platelet count was significantly improved at 2-year follow-up with 15 patients $(88 \%)$ achieving and maintaining a platelet count of $\left(\geq 150 \times 10^{9} / \mathrm{L}\right)$. Haematological normalisation was seen in $88 \%$ of patients. TMA event-free status was also achieved in 15 patients (88\%). Improvements in eGFR (increase of $\geq 15 \mathrm{~mL} / \mathrm{min} / 1.73 \mathrm{~m}^{2}$ ) continued by a 2-year follow-up in 10 of 17 patients (58\%). Further improvements in CKD stage ( $\geq 1$ stage) occurred in $71 \%$ of patients; serum creatinine decrease $(\geq 25 \%)$ was achieved in $75 \%$ of patients, and proteinuria decrease by ( $\geq 1$ grade) were seen in seven of nine patients. EuroQoL 5D score remained significantly improved $(\mathrm{p}=0.0001)$ at 2 years.

\section{Results of study C09-001R}

Results for the retrospective study are presented in table $2 .{ }^{31}$ No paediatric patient required new dialysis during treatment with eculizumab. Platelet count normalisation was observed 
Table 2 Efficacy results in paediatric patients enroled in aHUS (C009-001R)

\begin{tabular}{|c|c|c|c|}
\hline Efficacy parameters & $\begin{array}{l}\text { Patients <2 years } \\
(n=5)\end{array}$ & $\begin{array}{l}\text { Patients } 2 \text { to }<12 \text { years } \\
(n=10)\end{array}$ & $\begin{array}{l}\text { Patients <12 years } \\
(n=15)\end{array}$ \\
\hline Requiring new dialysis & 0 & 0 & 0 \\
\hline Patients with platelet count normalisation, n (\%) & $4 / 5(80)$ & $10 / 10(100)$ & $14 / 15(93)$ \\
\hline Complete TMA response*, n (\%) & $2 / 5(40)$ & $5 / 10(50)$ & $7 / 15(50)$ \\
\hline \multicolumn{4}{|l|}{ Daily TMA intervention rate†, median (range) } \\
\hline Before eculizumab & $1(0,2)$ & $<1(0.07,1.46)$ & $<1(0,2)$ \\
\hline On eculizumab treatment & $<1(0,<1)$ & $0(0,<1)$ & $0(0,<1)$ \\
\hline $\begin{array}{l}\text { Patients with eGFR improvement } \geq 15 \mathrm{~mL} / \mathrm{min} / \\
1.73 \mathrm{~m}^{2}, \mathrm{n}(\%)\end{array}$ & $2 / 5(40)$ & $6 / 10(60)$ & 8/15 (53) \\
\hline
\end{tabular}

for the majority of paediatric patients (14/15), and complete TMA response occurred in almost half of all patients (7/15). Improvement was observed in the daily TMA intervention rate which was lower during the eculizumab treatment compared with the intervention rate before eculizumab therapy. In 8 of 15 patients $(53 \%)$, an improvement in eGFR of $\left(\geq 15 \mathrm{~mL} / \mathrm{min} / 1.73 \mathrm{~m}^{2}\right)$ was observed.

\section{Duration of current severe clinical TMA manifestation (CO9-001R)}

Paediatric patients that had a shorter duration of severe TMA ( $<2$ months) were more likely to achieve complete TMA response and improvement in eGFR with eculizumab compared with patients with a longer duration (>2 months) of severe TMA (table 3$).{ }^{31}$ Platelet count normalisation and TMA event-free status were similar between the two times for TMA manifestation.

\section{Death}

In the retrospective study C009-001R, two deaths occurred but the manufacturer did not relate these to eculizumab treatment. One patient died after carotid artery surgery due to arterial stenosis. The other patient died due to graft versus host disease after undergoing bone marrow transplantation.

\section{Adverse events reported within study C08-002 and study C08-003}

Hypertension and upper respiratory tract infection were the most frequently reported adverse events in the two prospective studies (table 4). ${ }^{34}$ Headache and diarrhoea were also frequent problems experienced by patients. Leucopenia affected $16 \%$ of patients, although no reports of life-threatening infections occurred during the study phase.

\section{Adverse events reported within study C09-001R}

Fever and diarrhoea were the most frequently recorded adverse events in the retrospective study (table 5). ${ }^{34}$ Upper respiratory tract infections were also common with $32 \%$ patients reporting this adverse event while receiving eculizumab.

\section{DISCUSSION}

Results from the two prospective single arm studies comparing pre-eculizumab baseline measures with follow-up at 26 weeks showed TMA event-free status was achieved by $88 \%$ of patients in study C08-002 and $80 \%$ in study C08-003. Both prospective studies reported a statistically significant improvement in TMA intervention rate by the end of the study period $(p<0.0001)$. CKD stage improvement by $\geq 1$ stages was observed in both prospective studies, and median change in eGFR occurred in both studies $\left(20 \mathrm{~mL} / \mathrm{min} / 1.73 \mathrm{~m}^{2}\right.$ in study C08-002, and $5 \mathrm{~mL} / \mathrm{min} / 1.73 \mathrm{~m}^{2}$ in study C08-003). QoL scores were significantly improved in the short and long term.

Table 3 Results in paediatric patients (C09-001R) according to duration of current severe clinical TMA manifestation

\begin{tabular}{|c|c|c|}
\hline & \multicolumn{2}{|c|}{$\begin{array}{l}\text { Duration of current severe } \\
\text { clinical TMA manifestation }\end{array}$} \\
\hline & $\begin{array}{l}<2 \text { months, } \\
\mathrm{N}=10(\%)\end{array}$ & $\begin{array}{l}\text { >2 months, } \\
\mathrm{N}=5(\%)\end{array}$ \\
\hline $\begin{array}{l}\text { Platelet count } \\
\text { normalisation }\end{array}$ & $9(90)$ & $5(100)$ \\
\hline TMA event-free status* & $8(80)$ & $3(60)$ \\
\hline $\begin{array}{l}\text { Complete TMA } \\
\text { response } †\end{array}$ & $7(70)$ & 0 \\
\hline $\begin{array}{l}\text { eGFR improvement } \\
\geq 15 \mathrm{~mL} / \mathrm{min} / 1.73 \mathrm{~m}^{2}\end{array}$ & $7(70)$ & 0† \\
\hline \multicolumn{3}{|c|}{$\begin{array}{l}\text { *TMA event-free status is } \geq 12 \text { weeks of stable platelet count, no } \\
\text { PE/PI and no new dialysis. } \\
\text { †Complete TMA response is haematological normalisation plus at } \\
\text { least a } 25 \% \text { reduction in serum creatinine for a minimum of } \\
4 \text { weeks. } \\
\text { fOne patient achieved eGFR improvement after renal transplant. } \\
\text { Source: Electronic Medicines Compendium. }{ }^{31} \\
\text { eGFR, estimated glomerular filtration rate; PE, plasma exchange; } \\
\text { PI, plasma infusion; TMA, thrombotic microangiopathy. }\end{array}$} \\
\hline
\end{tabular}


Table 4 Patient incidence of adverse events reported in at least $10 \%$ of patients (US Food and Drug Administration (FDA))

\begin{tabular}{|c|c|c|c|}
\hline & C08-002 (n=17) & C08-003 (n=20) & Total $(n=37)$ \\
\hline Hypertension* & $8(47)$ & $5(25)$ & $13(35)$ \\
\hline \multicolumn{4}{|l|}{ Infections and infestations } \\
\hline Upper respiratory tract infection† & $5(29)$ & $8(40)$ & 13(35) \\
\hline Urinary tract infection & $4(24)$ & $2(10)$ & $6(16)$ \\
\hline \multicolumn{4}{|l|}{ Gastrointestinal disorders } \\
\hline Diarrhoea & $6(35)$ & $6(30)$ & $12(32)$ \\
\hline Vomiting & $5(29)$ & $3(15)$ & $8(22)$ \\
\hline Nausea & $4(24)$ & $3(15)$ & $7(19)$ \\
\hline Abdominal pain & 0 & $4(20)$ & $4(11)$ \\
\hline \multicolumn{4}{|l|}{ Nervous system disorders } \\
\hline Headache & $7(41)$ & $4(20)$ & $11(30)$ \\
\hline \multicolumn{4}{|l|}{ Blood and lymphatic system disorders } \\
\hline Anaemia & $6(35)$ & $3(15)$ & $9(24)$ \\
\hline Leucopenia & $4(24)$ & $2(10)$ & $6(16)$ \\
\hline \multicolumn{4}{|l|}{ Psychiatric disorders } \\
\hline Insomnia & $4(24)$ & $1(5)$ & $5(14)$ \\
\hline \multicolumn{4}{|c|}{ Respiratory, thoracic and mediastinal disorders } \\
\hline Cough & $2(12)$ & $3(15)$ & $5(14)$ \\
\hline Pharyngolaryngeal pain & $1(6)$ & $4(20)$ & $5(14)$ \\
\hline \multicolumn{4}{|c|}{ General disorders and administration site conditions } \\
\hline Fatigue & $3(18)$ & $1(5)$ & $4(11)$ \\
\hline Peripheral oedema & $3(18)$ & $1(5)$ & $4(11)$ \\
\hline Fever & $3(18)$ & $1(5)$ & $4(11)$ \\
\hline \multicolumn{4}{|l|}{ Ear and labyrinth disorders } \\
\hline Vertigo & $1(6)$ & $3(15)$ & $4(11)$ \\
\hline \multicolumn{4}{|c|}{ Musculoskeletal and connective tissue disorders } \\
\hline Pain in extremity & $1(6)$ & $3(15)$ & $4(11)$ \\
\hline
\end{tabular}

No deaths were reported during the study period or during the study extension phase in both prospective

Table 5 Adverse reactions occurring in at least $15 \%$ of patients less than 18 years of age enrolled in aHUS study C09-001R

\begin{tabular}{|c|c|c|c|c|}
\hline & $\begin{array}{l}<2 \text { years } \\
(n=5)\end{array}$ & $\begin{array}{l}2 \text { to } \\
<12 \text { years } \\
(n=10)\end{array}$ & $\begin{array}{l}12 \text { to } \\
<18 \text { years } \\
(n=4)\end{array}$ & $\begin{array}{l}\text { Total } \\
(n=19)\end{array}$ \\
\hline Fever & $4(80)$ & $4(60)$ & $1(25)$ & $9(47)$ \\
\hline Diarrhoea & $1(20)$ & $4(40)$ & $1(25)$ & $6(32)$ \\
\hline Vomiting & $2(40)$ & $1(10)$ & $1(25)$ & $4(21)$ \\
\hline $\begin{array}{l}\text { Upper } \\
\text { respiratory } \\
\text { tract } \\
\text { infection* }\end{array}$ & $2(40)$ & $3(30)$ & $1(25)$ & $6(32)$ \\
\hline Cough & $3(60)$ & $2(20)$ & $0(0)$ & $5(26)$ \\
\hline $\begin{array}{l}\text { Nasal } \\
\text { congestion }\end{array}$ & $2(40)$ & $2(20)$ & $0(0)$ & $4(21)$ \\
\hline Tachycardia & $2(40)$ & $2(20)$ & $0(0)$ & $4(21)$ \\
\hline
\end{tabular}

*Includes the preferred terms upper respiratory tract infection and nasopharyngitis.

Source: US FDA. ${ }^{34}$

aHUS, atypical haemolytic uraemic syndrome; FDA, Food and Drug Administration. studies. The 40 and 114-week follow-up data (C08-003) indicated that this improvement was maintained. In the retrospective study (C09-001R), none of the paediatric patients needed new dialysis during treatment with eculizumab, and platelet count normalisation was observed in 14 of the 15 patients in this uncontrolled study. Additional analysis suggested that patients treated with eculizumab by $<2$ months had a better response to treatment. The maintenance of the beneficial effects of eculizumab over time in the aHUS trial is consistent with the experience of $195 \mathrm{PNH}$ patients over 66 months on eculizumab. There were no treatment-related deaths and treatment was well tolerated with no evidence for cumulative toxicity and a decreasing occurrence of adverse effects over time. Importantly, PNH patients also showed a time-dependent improvement in renal function with $93.1 \%$ of patients showing improvement or stabilisation of a CKD score at 36 months. ${ }^{43}$

Thus, overall, eculizumab appears to be a highly effective treatment for aHUS, although it was not compared head to head with optimal plasmapheresis (current best practice in the UK). However, the absence of the requirement for new dialysis or deaths over 114-week follow-up in C08-002 suggests that the outcome for eculizumab is significantly better than that recently 
reported for aHUS treated with plasmapheresis alone in adults with respect to rates of death $(0.8 \%)$ or ESRD ( $46 \%$ at 1 year). ${ }^{7}$ Likewise, the absence of death, lack of need for new dialysis and improvement in eGFR in the children treated in the retrospective trial C009-001R is encouraging given previous reports of 1-year mortality of $6.7 \%$ and ESRD rate of $16 \% .^{7}$ However, there are some indications for caution with a longer term use of eculizumab. First, erythrocytes and platelets have extensive iC3b and C3d deposited on them through opsonisation, following inhibition of complement at the C5 level. This can shorten their half-life with increased clearance through the reticuloendothelial system and has led to recurrent anaemia and transfusion requirement in some patients with $\mathrm{PNH} .{ }^{44}{ }^{45}$ Second, renal biopsy performed in three patients with either dense deposit disease or C3 glomerulopathy before and after eculizumab treatment ${ }^{46}$ all showed no significant reduction in C3 or C5b-9 staining and de novo monoclonal staining for IgGK in the same distribution as C3 and C5b-9, mimicking monoclonal immunoglobulin deposition disease on posttreatment biopsies. Staining of the $\gamma$ heavy chain was restricted to the IgG2 and IgG4 subclasses, suggesting binding of the monoclonal eculizumab to C5 in renal tissue. The long-term effects of this drug-tissue interaction are not known.

Most orphan drugs submitted for regulatory approval are based on RCTs that follow generally accepted rules and guidance. ${ }^{47}$ However, randomising patients with ultra-orphan diseases such as aHUS may be impractical due to the difficulty of recruiting sufficient patients, and because the risk of disease progression or death is very high in this population ethical considerations may prevent the use of RCTs, or patient withdrawal studies. Therefore, transparent reporting of patient recruitment and selection are needed to inform decision makers if the findings are applicable to all patients with aHUS. Results may not be generalisable to non-specialist centres and non-expert use. The limitations of the prospective studies are that the average age of patients was 28 years with an age range of 13-68 years. A more representative sample would have included a paediatric population to reflect this important group of patients with the disease. Owing to the absence of a control group, inference of treatment effects may be confounded and it remains uncertain whether all patients would respond to eculizumab or even require treatment as reports indicate that some patients with aHUS, for example, those with CD46 mutations, experience natural recovery without any therapy. ${ }^{48}$ There is also potential for publication bias in evaluating the retrospective study. The initial two case reports of treatment of aHUS with eculizumab were published in the $N$ Engl J Med in $2009^{49} 50$ and have been followed by numerous other positive case reports which have contributed significantly to the field in informing best use of eculizumab. ${ }^{22}{ }^{51}$ However, it is less clear if negative data would be similarly published. Second, the case reports which preceded the prospective trials by 4 years have the potential for skewing perception in the field. An example of this may exist with extrapolation of use of eculizumab to Stx-HUS. Here, despite an initial case report suggesting a benefit of eculizumab in three children with Escherichia coli O157-mediated Stx-HUS, ${ }^{52}$ the summary of results from a large subgroup of adults affected with $E$ coli O104-mediated Stx-HUS $(\mathrm{n}=491)^{53} 54$ was that eculizumab and PE (n=193) offered no additional advantage compared to $\mathrm{PE}(\mathrm{n}=241)$ or to best practice supportive care alone $(n=57)$ in a non-randomised trial, where the most severely affected adult patients received eculizumab in addition to PE. It is therefore necessary to examine this question in a formal RCT looking at children and adults diagnosed with Stx-HUS.

The lack of use of an RCT for aHUS may also be questionable despite the caveats regarding recruitment with orphan diseases. The 20 patients in trial C08-003 on chronic plasmapheresis were all removed from treatment and converted to eculizumab. It would have been possible to perform a prospective randomised crossover trial with these patients in two groups of 10 which would have yielded useful information. For example, a recent double blind placebo controlled crossover trial performed in 14 patients with myasthenia gravis showed that 6 of 7 patients treated with eculizumab for 16 weeks $(86 \%)$ achieved the primary end point of a three-point reduction in Quantitative Myasthenia Gravis (QMG) score. When both treatment periods were examined, overall change in mean QMG score was significantly different between eculizumab and placebo $(\mathrm{p}<0.0001) .^{55}$ Complete reporting is needed in orphan diseases to facilitate the evaluation of the clinical and cost effectiveness of treatment and provide clinicians and policy makers with sufficient evidence to make informed decisions. Establishing global patient registries, or utilising data from the International Registry of Recurrent and Familial HUS established in Italy ${ }^{3}$ would provide insights into the natural history of this rare disease. Long-term follow-up data need to be made available for all outcomes. Many outcomes were biological markers. Ideally, where surrogate outcomes are substituted for clinical endpoints in order to predict clinical benefit, these should be validated to demonstrate the relationship between surrogate and patient-related outcome. ${ }^{56}$

The safety data indicated that adverse events in the uncontrolled prospective studies are frequent, with hypertension and upper respiratory tract infection affecting about a third of patients, though it remains unclear if these are treatment-related or complications of aHUS. The potentially serious complication of leucopenia affected $16 \%$ of patients, although no serious meningococcal infections were reported in the first phase or follow-up period. Only adverse events occurring in at least $10 \%$ of patients were reported and therefore, rare but serious complications of treatment could remain unreported. In the retrospective study C09-001R, adverse events were only reported using a higher threshold of 
$\geq 15 \%$ of patients. Fever was a frequently reported adverse event in $47 \%$ of patients. Upper respiratory tract infection and diarrhoea affected about a third of patients. One case of meningococcal infection was reported in a patient with aHUS, which occurred in study C09-001R after the data cut-off period. The patient fully recovered and remained on eculizumab. Thus, the safety data in the short-term treatment of aHUS is reassuring. However, risks of meningococcal sepsis remain throughout treatment duration because late complement pathway deficiencies predispose to meningococcal infections by the absence of meningococcal lysis through classical and alternative pathways. ${ }^{57}$ Consequently, protection against meningococcal disease by antibody-mediated killing becomes essential. All patients need to be vaccinated against Neisseria meningitidis and many physicians also provide antibiotic prophylaxis, for example with ciprofloxacin ${ }^{58}$ as the commonest European meningococcal serotype, (type B), is not included in the tetravalent vaccine. Patient education about this potential complication on eculizumab treatment will be critical to facilitate rapid treatment with appropriate antibiotics as soon as there is any suspicion of meningococcal disease. Levels of side effect monitoring and awareness of meningococcus are very high within trials but may not be maintained outside trial settings.

Poor response to meningococcal vaccination has been reported in two patients with renal transplants on immunosuppression, one of whom developed meningococcal septicaemia which responded to prompt resuscitation and empiric antibiotic treatment. ${ }^{58}$ Subsequent repeat vaccination, including a different conjugate vaccine preparation, also failed to induce immunity. ${ }^{58} \mathrm{~A}$ further transplant patient had waning but protective titres to meningococcus $\mathrm{C}$ vaccination. ${ }^{59}$ Therefore, if eculizumab becomes used more widely to facilitate renal transplantation for patients with underlying aHUS, there needs to be an awareness of the potential for complication by meningococcal disease despite prior vaccination. Also, the efficacy of vaccination in eculizumab-treated patients receiving immunosuppressive therapy cannot be assumed. Patients should preferably be vaccinated before receiving immunosuppressive therapy. The trial data may also not be extrapolatable to proposed use of eculizumab to facilitate de novo transplantation in those patients with aHUS established long term on dialysis. Patients on dialysis have poor response to vaccinations, for example, failed seroconversion and loss of immunity with time after hepatitis B vaccination. ${ }^{60}$

Following completion of the systematic review, the Advisory Group for National Specialised Services in the UK has advised government ministers that there is evidence of clinical effectiveness for the treatment of aHUS; ministers have since requested further data on its affordability ${ }^{61}$ and findings are expected to be reported by the National Institute for Health and Care Excellence (NICE) at the end of 2013.

\section{CONCLUSIONS}

The results from three, small, uncontrolled studies indicate that eculizumab is clinically effective in patients with aHUS and reduces TMA activity as measured by TMA event-free status, and normalises platelet count in the majority of patients. No severe life-threatening adverse events were associated with treatment. Study extension results suggest the benefits of treatment are sustained. However, due to the study design limitations, inference of treatment effects may be confounded by the lack of a control group.

Contributors PT, JR and EK conceived the idea for the study. AC devised and performed the electronic search for studies, deduplicate and checked the results, acquired study reports and reran the update search. JR and EK undertook the study selection and data extraction. PT and $A B$ undertook cross-checking of data. JR, EK, PT, AB and AR undertook the data analysis. $J R$ and $A R$ wrote the initial draft of the manuscript. EK, PT, $A B$ and $A C$ provided critical comments for the initial draft and revised versions, and contributed to the interpretation of the results. All authors read and approved the final version of the manuscript.

Funding This project was funded by the NIHR Health Technology Assessment programme project number (11/91/01). The views and opinions expressed therein are those of the authors and do not necessarily reflect those of the Department of Health.

Competing interests AR was supported by a Wellcome Trust Intermediate Clinical Fellowship award (WT085226) and received fees from Alexion Pharmaceuticals for speaking at educational meetings and to attend National and Global Expert Advisory Committee panels.

Provenance and peer review Not commissioned; externally peer reviewed.

Data sharing statement No unpublished data are held. All data are in the public domain.

Open Access This is an Open Access article distributed in accordance with the Creative Commons Attribution Non Commercial (CC BY-NC 3.0) license, which permits others to distribute, remix, adapt, build upon this work noncommercially, and license their derivative works on different terms, provided the original work is properly cited and the use is non-commercial. See: http:// creativecommons.org/licenses/by-nc/3.0/

\section{REFERENCES}

1. Gasser C, Gautier E, Steck A, et al. Hamolytisch-uramische syndrome: bilateral Nierenrindennekrosen bei akuten erworbenen hamolytischen Anamien. Schweiz Med Wochenschr 1955;85:905.

2. Michael M, Elliott EJ, Craig J, et al. Interventions for hemolytic uremic syndrome and thrombotic thrombocytopenic purpura: a systematic review of randomized controlled trials. Am J Kidney Dis 2009;53:259-72.

3. Besbas N, Karpman D, Landau D, et al. A classification of hemolytic uremic syndrome and thrombotic thrombocytopenic purpura and related disorders. Kidney Int 2006;70:423-31.

4. Loirat C, Fremeaux-Bacchi V. Atypical hemolytic uremic syndrome. Orphanet J Rare Dis 2011;6:1-30.

5. Hughes D, Tunnage B, Yeo S. Drugs for exceptionally rare diseases: do they deserve special status for funding? QJM 2005;98:829-36.

6. Taylor C, Machin S, Wigmore SJ, et al. Clinical practice guidelines for the management of atypical haemolytic uraemic syndrome in the United Kingdom. Br J Haematol 2010;148:37-47.

7. Fremeaux-Bacchi V, Fakhouri F, Garnier A, et al. Genetics and outcome of atypical hemolytic uremic syndrome: a nationwide French series comparing children and adults. Clin J Am Soc Nephrol 2013;8:554-62.

8. Joseph C, Gattineni J. Complement disorders and hemolytic uremic syndrome. Curr Opin Pediatr 2013;25:209-15.

9. Sharma AP, Greenberg CR, Prasad AN, et al. Hemolytic uremic syndrome (HUS) secondary to cobalamin C (cblC) disorder. Pediatr Nephrol 2007;22:2097-103. 
10. Palanca D, Garcia-Cazorla A, Ortiz J, et al. cblE-type homocystinuria presenting with features of haemolytic-uremic syndrome in the newborn period. JIMD Rep 2013;8:57-62.

11. Lemaire M, Frémeaux-Bacchi V, Schaefer F, et al. Recessive mutations in DGKE cause atypical hemolytic-uremic syndrome. Nat Genet 2013;45:531-6.

12. Noris M, Remuzzi G. Atypical hemolytic-uremic syndrome. N Engl $J$ Med 2009;361:1676-87.

13. Noris M, Caprioli J, Bresin E, et al. Relative role of genetic complement abnormalities in sporadic and familial aHUS and their impact on clinical phenotype. Clin J Am Soc Nephrol 2010;5:1844-59.

14. Clark W. Thrombotic microangiopathy: current knowledge and outcomes with plasma exchange. Semin Dial 2012; 25:214-19.

15. Zuber J, Le Quintrec M, Sberro-Soussan R, et al. New insights into postrenal transplant hemolytic uremic syndrome. Nat Rev Nephrol 2011;7:23-35.

16. Ariceta G, Besbas N, Johnson S, et al. Guideline for the investigation and initial therapy of diarrhea-negative hemolytic uremic syndrome. Pediatr Nephrol 2009;24:687-96.

17. Rock G, Clark B, Sutton D, et al. The Canadian apheresis registry Transfus Apher Sci 2003;29:167-77.

18. Rees L. Atypical HUS: time to take stock of current guidelines and outcome measures? Pediatr Nephrol 2013;28:675-7.

19. Carter $\mathrm{C}$, Benador N. Therapeutic plasma exchange for the treatment of pediatric renal diseases in 2013. Pediatr Nephrol 2013; [Epub ahead of print].

20. Kavanagh D, Richards A, Goodship T, et al. Transplantation in atypical hemolytic uremic syndrome. Semin Thromb Hemost 2010;36:653-9.

21. Saland JM, Ruggenenti P, Remuzzi G. Liver-kidney transplantation to cure atypical hemolytic uremic syndrome. J Am Soc Nephrol 2009;20:940-9.

22. Zuber J, Fakhouri F, Roumenina L, et al. Use of eculizumab for atypical haemolytic uraemic syndrome and C3 glomerulopathies. Nat Rev Nephrol 2012;8:643-57.

23. Hillmen P, Muus P, Röth A, et al. Long-term safety and efficacy of sustained eculizumab treatment in patients with paroxysmal nocturnal haemoglobinuria. Br J Haematol 2013; 162:62-73.

24. Schmidtko J, Peine S, El-Housseini Y, et al. Treatment of atypical hemolytic uremic syndrome and thrombotic microangiopathies: a focus on eculizumab. Am J Kidney Dis 2013;61:289-99.

25. Moher D, Liberati A, Tetzlaff J, et al. Preferred Reporting Items for Systematic Reviews and Meta-Analyses: the PRISMA statement. Int J Surg 2010:8:336-41.

26. Chambers $\mathrm{D}$, Rodgers $\mathrm{M}$, Woolacott $\mathrm{N}$. Not only randomized controlled trials, but also case series should be considered in systematic reviews of rapidly developing technologies. J Clin Epidemiol 2009;62:1253-60.

27. Legendre C, Babu S, Furman R, et al. Safety \& efficacy of eculizamab in aHUS patients resistant to plasma therapy: interim analysis from a phase II trial. J Am Soc Nephrol 2011;21:201.

28. Bedrosian $\mathrm{C}$, Babu S, Furman R, et al. Eculizumab is effective in patients resistant to plasma exchange/infusion with atypical hemolytic uremic syndrome (AHUS): 23 rd Congress of the International Society on Thrombosis and Haemostasis: Kyoto, Japan 2011.

29. Loirat $\mathrm{C}$, Babu S, Furman R, et al. Eculizumab in adolescents/adult patients with atypical hemolytic uremic syndrome resistant to plasma exchange/infusion: a phase II efficacy and safety study. Pediatr Nephrol 2011;26:1660-61.

30. Greenbaum L, Babu S, Furman R, et al. Continued improvements in renal function with sustained eculizumab (ECU) in patients (PTS) with typical hemolytic uremic syndrome (aHUS) resistant to plasma exchange/infusion (PS/PI). American Society of Nephrology Kidney Week, Philadelphia, 2011.

31. Summaries of Product Characteristics (Soliris): The electronic Medicines Compendium, 2012. http://www.medicines.org.uk/emc/ medicine/19966

32. Licht $C$, Muus $\mathrm{P}$, Legendre $\mathrm{C}$, et al. A phase II study of eculizumab in adolescent/adult patients with atypical hemolytic uremic syndrome (aHUS) receiving chronic plasma exchange/infusion: interim efficacy and safety analysis. Pediatr Nephrol 2011;26:1591-731.

33. Goodship T, Muus P, Legendre C, et al. Interim analysis of phase II efficacy and safety data for eculizumab in patients with atypical hemolytic uremic syndrome (aHUS) receiving chronic plasma exchange/infusion. Mol Immunol 2011;48:1712.

34. Soliris (eculizumab) highlights of prescribing information. US Food and Drug Administration; 2007. http://www.accessdata.fda.gov/ drugsatfda_docs/label/2011/125166s172lbl.pdf
35. Licht $\mathrm{C}$, Muus $\mathrm{P}$, Legendre $\mathrm{C}$, et al. A phase II study of eculizumab in patients with atypical hemolytic uremic syndrome (AHUS) receiving chronic plasma exchange/infusion: interim analysis. $J$ Thromb Haemost 2011;9(s2):499-711.

36. Muus $\mathrm{P}$, Legendre $\mathrm{C}$, Douglas $\mathrm{K}$, et al. Safety \& efficacy of eculizumab in aHUS patients on chronic plasma therapy: interim analysis of a phase II trial. American Society of Nephrology (ASN) Annual Meeting on Friday, November 19; 2010.

37. Legendre $\mathrm{C}$, Licht $\mathrm{C}$, Muus $\mathrm{P}$, et al. Terminal complement inhibitor eculizumab in atypical hemolytic-uremic syndrome. N Engl J Med 2013;368:2169-81.

38. Simonetti GD, Gruppo RA, Rodig N, et al. Eculizumab therapy for atypical hemolytic uremic syndrome (aHUS) in pediatric patients: efficacy and safety outcomes from a retrospective study. Pediatr Nephrol 2011;26:1663.

39. Gruppo R, Rodig N, Vilalta R, et al. Eculizumab (ECU) therapy for atypical hemolytic uremic syndrome (AHUS) in pediatric patients: efficacy and safety outcomes from a retrospective study. 23rd Congress of the International Society on Thrombosis and Haemostasis 57th Annual SSC Meeting Kyoto Japan, 2011.

40. Licht $\mathrm{C}$, Muus $\mathrm{P}$, Legendre $\mathrm{C}$, et al. Ph II study of eculizumab (ECU) in patients (PTS) with atypical hemolytic uremic syndrome (aHUS) receiving chronic plasma exchange/infusion (PE/PI). J Am Soc Nephrol 2011;22:197.

41. Licht $\mathrm{C}$, Muus $\mathrm{P}$, Legendre $\mathrm{C}$, et al. Eculizumab (ECU) safety and efficacy in atypical hemolytic uremic syndrome (aHUS) patients with long disease duration and chronic kidney disease (CKD): 2-year results 54th ASH annual meeting and exposition. Atlanta, Georgia, USA: World Congress Center, 2012.

42. Greenbaum L, Legendre C, Babu S, et al. Eculizumab (ECU) in atypical hemolytic uremic syndrome (aHUS) patients with progressing thrombotic microangiopathy (TMA): 2-year data 54th ASH annual meeting and exposition. Atlanta, Georgia, USA: World Congress Center, 2012.

43. Hillmen $\mathrm{P}$, Hall $\mathrm{C}$, Marsh J, et al. Eculizumab, a C5 complement-blocking antibody, controls hemolysis in paroxysmal nocturnal hemoglobinuria (PNH) with responses maintained over a prolonged period of therapy. Blood 2003;102:509a-10a.

44. Risitano A. Paroxysmal nocturnal hemoglobinuria and the complement system: recent insights and novel anticomplement strategies. Adv Exp Med Biol 2013;735:155-72.

45. Lindorfer MA, Pawluczkowycz AW, Peek EM, et al. A novel approach to preventing the hemolysis of paroxysmal nocturnal hemoglobinuria both complement-mediated cytolysis and C3 deposition are blocked by a monoclonal antibody specific for the alternative pathway of complement. Blood 2010;115:2283-91.

46. Herlitz L, Bomback A, Markowitz G, et al. Pathology after eculizumab in dense deposit disease and C3 GN. J Am Soc Nephrol 2013;23:1229-37.

47. Guidelines on clinical trials in small populations. London: European Medicines Agency, 2006. http://www.ema.europa.eu/docs/en_GB/... guideline/...WC500003615.pdf

48. Caprioli J, Noris M, Brioschi S, et al. Genetics of HUS: the impact of $\mathrm{MCP}, \mathrm{CFH}$ and IF mutations on clinical presentation, response to treatment, and outcome. Blood 2006;108:1267-79.

49. Gruppo RA, Rother RP. Eculizumab for congenital atypical hemolytic-uremic syndrome. N Engl J Med 2009;360:544-6.

50. Nürnberger J, Philipp T, Witzke O, et al. Eculizumab for atypical hemolytic-uremic syndrome. N Engl J Med 2009; 360:542-4.

51. Campistol J, Arias M, Ariceta G, et al. An update for atypical haemolytic uraemic syndrome: diagnosis and treatment. A consensus document. Nefrologia 2013;33:27-45.

52. Lapeyraque A, Malina M, Fremeaux-Bacchi V, et al. Complement blockade in severe Shiga-toxin-associated HUS. N Engl J Med 2011:364:2561-3

53. Kielstein J, Heiden A, Beutel G, et al. Renal function and survival in 200 patients undergoing ECMO therapy. Nephrol Dial Transplant 2013;28:86-90.

54. Karpman D, Tati R. Complement activation in thrombotic microangiopathy. Hamostaseologie 2013;33:96-104.

55. Howard JJ, Barohn R, Cutter G, et al. A randomized, double-blind placebo-controlled phase II study of eculizumab in patients with refractory generalized myasthenia gravis. Muscle Nerve 2013;48:76-84.

56. Elston J, Taylor R. Use of surrogate outcomes in cost-effectiveness models: a review of United Kingdom health technology assessment reports. Int J Technol Assess Health Care 2009;25:6-13.

57. Ram S, Lewis L, Rice P. Infections of people with complement deficiencies and patients who have undergone splenectomy. Clin Microbiol Rev 2010;23:740-80. 
58. Struijk G, Bouts A, Rijkers G, et al. Meningococcal sepsis complicating eculizumab treatment despite prior vaccination. $A m \mathrm{~J}$ Transplant 2013;13:819-20.

59. Zlamy M, Hofer J, Elias J, et al. Immunogenicity of meningococcus $C$ vaccination in a patient with atypical hemolytic uremic syndrome (aHUS) on eculizumab therapy. Pediatr Transplant 2012;16:246-50.
60. Bel'eed K, Wright M, Eadington $\mathrm{D}$, et al. Vaccination against hepatitis $B$ infection in patients with end stage renal disease. Postgrad Med J 2002;78:538-40.

61. Advisory Group for National Specialised Services. Statement from AGNSS regarding eculizumab and tafamidis, 2013. http://www. specialisedservices.nhs.uk/news/view/132 